\title{
Sex differences in cortical and subcortical human brain
}

\section{anatomy [version 1; peer review: 1 approved, 1 approved with}

\section{reservations]}

\author{
Timothy J. Herron (iD) 1 Xiaojian Kang 1,2, David L. Woods ${ }^{1-3}$ \\ ${ }^{1}$ Human Cognitive Neurophysiology Lab, Department of Veterans Affairs Medical Centre, Martinez, California, 94553, USA \\ ${ }^{2}$ Department of Neurology and Center for Neuroscience, UC Davis, Sacramento, California, 95616, USA \\ ${ }^{3}$ UC Davis Center for Mind and Brain, UC Davis, Davis, California, 95616, USA
}

\section{V1 First published: 08 Apr 2015, 4:88 \\ https://doi.org/10.12688/f1000research.6210.1}

Latest published: 08 Apr 2015, 4:88

https://doi.org/10.12688/f1000research.6210.1

\begin{abstract}
Previous research has reported many sex differences in cortical and subcortical anatomy, but only a subset of findings is consistent across studies. Here, we used improved Freesurfer-based automated methods to analyze the properties of the cortex and seven subcortical structures in young, right-handed subjects (69 male and 69 female), carefully matched in age and education. Significant sex differences were observed. Females had greater gyral complexity (i.e., greater bending energy). In contrast, males had greater unadjusted cortical surface area (+10.3\%), but area differences were reduced (to $+2.8 \%$ ) when area was adjusted for total intracranial volume (ICV). There were no significant omnibus sex differences in cortical thickness. Males showed larger unadjusted subcortical gray matter structural volumes, as well as larger ICV-adjusted volumes in the amygdala. These results help to resolve some of the inconsistencies in previous studies of sex differences in brain anatomy.
\end{abstract}

Keywords

Gender, Frontal, Temporal, Parietal, Occipital, Limbic, Normalization, Scaling

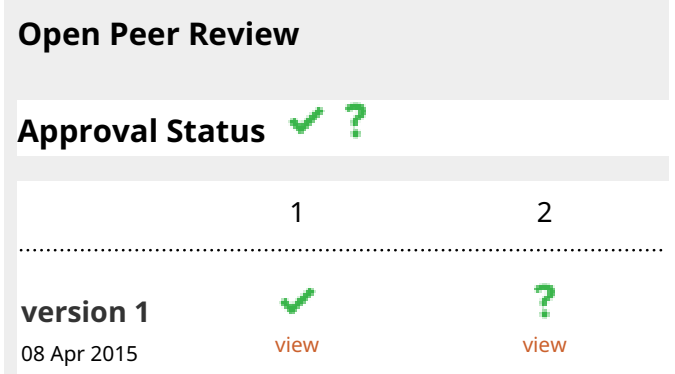

1. Lutz Jäncke 1 , University of Zurich, Zurich, Switzerland

2. Gina Rippon, Aston University, Birmingham, UK Any reports and responses or comments on the article can be found at the end of the article. 
Corresponding author: Timothy J. Herron (tjherron@ebire.org)

Competing interests: No competing interests were disclosed.

Grant information: This research was supported by a VA Research and Development Grants CX000583 and CX001000 to DLW. The content is solely the responsibility of the authors and does not necessarily represent the official views of Department of Veterans Affairs or the U.S. Government.

The funders had no role in study design, data collection and analysis, decision to publish, or preparation of the manuscript.

Copyright: (c) 2015 Herron TJ et al. This is an open access article distributed under the terms of the Creative Commons Attribution License, which permits unrestricted use, distribution, and reproduction in any medium, provided the original work is properly cited. Data associated with the article are available under the terms of the Creative Commons Zero "No rights reserved" data waiver (CC0 1.0 Public domain dedication).

How to cite this article: Herron TJ, Kang $X$ and Woods DL. Sex differences in cortical and subcortical human brain anatomy [version 1; peer review: 1 approved, 1 approved with reservations] F1000Research 2015, 4:88 https://doi.org/10.12688/f1000research.6210.1

First published: 08 Apr 2015, 4:88 https://doi.org/10.12688/f1000research.6210.1 


\section{Introduction}

Brain structure has been reported to differ between male and female brains (Bostan et al., 2013; Inano et al., 2013; Kim et al., 2012; Koolschijn \& Crone, 2013; Ruigrok et al., 2014), but locations showing sex differences have varied across studies. In the present study, we used novel, improved automated methods to analyze sexrelated differences in brain structure in 69 right-handed males and 69 right-handed females, who had been carefully matched in age and education. By establishing consistent sample characteristics, image scan quality, segmentation, and corrections for overall intracranial volume, we were able to identify sources of inconsistency in previous studies, and provide a clearer picture of sex differences in brain anatomy. We use two independently collected and previously analyzed, high-quality anatomical image sets to increase confidence in our results.

Sex differences in overall brain size are consistently observed in all studies: adult males have $7.4 \%-11.5 \%$ greater gray matter brain volume than females and show a $10.4 \%-13.6 \%$ increase in intracranial volume (ICV) (Good et al., 2001; Ruigrok et al., 2014). Differences between the sexes of roughly this magnitude are evident by age five (Brain Development Cooperative, 2012; Koolschijn \& Crone, 2013), or even earlier in development (Dekaban, 1977; Luders \& Toga, 2010). Substantial differences in volume remain even when accounting for body size difference (Sacher et al., 2013), although it should be noted that no body size covariate has been yet found to be fully adequate to account for overall brain size within most human adult populations (Peters et al., 1998).

When considering regional sex differences however, results have been less consistent across studies. As seen in Table 1, classical results report inconsistent sex differences throughout in the

Table 1. Regional cortical sex differences reported in previous studies using whole-brain MRI. Magenta; Female > Male; Cyan: Male > Female, L Left Hemisphere, R Right Hemisphere (a) Center column: Consistent VBM results from a recent meta-analysis (Ruigrok et al., 2014): (b) Right Columns: Area and thickness cortical measurements and subcortical volume measurements of $\mathbf{N}$ : Luders et al., 2006, G: Luders et al., 2009, I: Im et al., 2006. B Brain Development Cooperative Group, 2012; J: Jiang et al., 2013; T: Inano et al., 2013; F: Fjell et al., 2009, K: Koolschijn Crone, 2013; S: Sowell et al., 2007; Z: Im et al., 2008; Y: Lentini et al., 2013. X Neufang et al., 2009.

\begin{tabular}{|r|c|c|c|}
\hline & $\begin{array}{c}\text { VBM (Ruigrok } \\
\text { et al., 2014) }\end{array}$ & Area & Thickness \\
\hline Frontal/Cingulate & & & \\
\hline Cingulate & & & \\
\hline Cingulate Sulcus & & & \\
\hline Anterior Cingulate & L, R & Y & \\
\hline Posterior Cingulate & L, R & & \\
\hline Prefrontal Cortex & & $K$ & \\
\hline Frontal Pole & R, R, L & & S \\
\hline Middle Frontal Gyrus & R & & JL \\
\hline Paracentral Gyrus & & & \\
\hline Precentral Gyrus & L & & N \\
\hline
\end{tabular}

\begin{tabular}{|c|c|c|c|}
\hline & $\begin{array}{l}\text { VBM (Ruigrok } \\
\text { et al., 2014) }\end{array}$ & Area & Thickness \\
\hline Inferior Frontal Gyrus & $\mathbf{R}$ & YR & \\
\hline \multicolumn{4}{|l|}{ Pars Orbitalis } \\
\hline Pars Opercularis & $\mathbf{R}$ & & \\
\hline Pars Triangularis & $\mathbf{R}$ & & \\
\hline Superior Frontal Gyrus & & & J \\
\hline Superior Frontal Sulcus & & GL & $\mathbf{N}$ \\
\hline \multicolumn{4}{|l|}{ Temporal/Insular } \\
\hline Insula & $L, \mathbf{R}$ & & \\
\hline \multicolumn{4}{|l|}{ Inferior Insula } \\
\hline \multicolumn{4}{|l|}{ Middle Insula } \\
\hline \multicolumn{4}{|l|}{ Superior Insula } \\
\hline \multicolumn{4}{|l|}{ Temporal Lobe } \\
\hline Anterior Temporal Lobe & & & $\mathbf{N}$ \\
\hline Superior Temporal Gyrus & & GL & SR \\
\hline Heschl's gyrus & $\mathbf{R}$ & & \\
\hline Planum Temporale & $\mathbf{R}$ & & \\
\hline Temporal Pole & $L, R$ & & \\
\hline Superior Temporal Sulcus & & & SR \\
\hline Middle Temporal Gyrus & & & $N L$ \\
\hline \multicolumn{4}{|l|}{ Inferior Temporal Gyrus } \\
\hline Parahippocampal & $L, R, \mathbf{L}$ & & \\
\hline Occipital/Parietal & & & \\
\hline
\end{tabular}

\begin{tabular}{|c|c|c|c|}
\hline Parietal Lobe & & K & \\
\hline Post-central Gyrus/Sulcus & & & $\mathrm{N}, \mathrm{IL}$ \\
\hline \multicolumn{4}{|l|}{ Sub-central Gyrus } \\
\hline Superior Parietal Gyrus & & & IL \\
\hline \multicolumn{4}{|l|}{ Intraparietal Sulcus } \\
\hline Inferior Parietal Lobe & & & SR \\
\hline \multicolumn{4}{|l|}{ Angular Gyrus } \\
\hline Supramarginal Gyrus & & & SR \\
\hline Parietal Operculum & $\mathbf{R}$ & & \\
\hline Occipital Lobe & & & $S$ \\
\hline \multicolumn{4}{|l|}{ Calcarine Sulcus } \\
\hline Lingual Gyrus & & Y & SL \\
\hline Lateral Occipital & $L$ & & \\
\hline Precuneus & $L, R, \mathbf{L}, \mathbf{R}$ & & \\
\hline \multicolumn{4}{|l|}{ Middle Occpital Gyrus } \\
\hline Subcortical & & \multicolumn{2}{|r|}{ Volume } \\
\hline Amygdala & $L, R$ & \multicolumn{2}{|r|}{$Y L, X$} \\
\hline Putamen & $L, R$ & \multicolumn{2}{|r|}{$B, \mathbf{T}, F$} \\
\hline Caudate & & \multicolumn{2}{|r|}{ GL, GR } \\
\hline Hippocampus & $L, R$ & \multicolumn{2}{|r|}{$\mathbf{T}, F, \mathbf{X}$} \\
\hline Cerebellum & $L, R, \mathbf{R}$ & \multicolumn{2}{|r|}{$B, Y$} \\
\hline Pallidum & $L$ & \multicolumn{2}{|r|}{$\mathbf{T}, F$} \\
\hline Thalamus & L, $\mathbf{R}$ & \multicolumn{2}{|r|}{$\mathbf{T}, F$} \\
\hline
\end{tabular}


cortex, but a recent meta-analysis of several voxel-based morphometry (VBM) studies shows suggested reliable regional sex-related variations (Good et al., 2001; Ruigrok et al., 2014). However, most of the VBM differences have not been replicated in more accurate surface-based measurements of thickness and area/volume (Luders et al., 2006; Sowell et al., 2007). Considering surface-based studies, the results in Table 1 suggest that females may hold relative size advantages in superior temporal cortex, parietal lobe, and frontal lobe, but there appears to be little agreement on which hemisphere and/or intra-lobar regions are affected, suggesting that the results may vary with the analytical procedure used (Fischl et al., 1999b; Im et al., 2010; Jiang et al., 2013; Leonard et al., 2008; Luders et al., 2006; Sowell et al., 2007; Van Essen, 2005). Critically, there is no single widely-used standard for normalizing brain volumes to ICV, an issue contributing to the inconsistency in results, with some groups asserting that sex differences largely disappear when the overall gray matter (GM) difference noted above is removed with proper scaling covariates (Im et al., 2008).

Studies of sex differences in subcortical structures have also produced conflicting results (Table 1). For example, VBM studies show greater relative hippocampal volume in men than women, while other studies show the opposite result (Inano et al., 2013; Sowell et al., 2007; Szabo et al., 2006). Similar inconsistences are found when examining sex differences in the basal ganglia (Filipek et al., 1994; Inano et al., 2013) and the thalamus (Bramen et al., 2011; Inano et al., 2013). Ultimately, age-related changes may be playing a crucial role in these discrepant results (Sowell et al., 2004). However, the amygdala is one structure that appears consistently larger in men in most studies (Goldstein et al., 2001; Good et al., 2001) (Inano et al., 2013).

These inconsistencies in the literature on sex differences may be caused by many factors, including differences in sample characteristics, image scan quality, segmentation approaches, and statistical procedures. In the present study, we address some of these inconsistencies by using a well matched, young, healthy population of male and female subjects, imaged by one operator on a single scanner, and analyzed with automated segmentation and coregistration procedures using multiscale data analysis. Studying a wellmatched young adult population avoids the potential problem of differential age-related changes in brain size rates of change for males and females (Crivello et al., 2014; Thambisetty et al., 2010) (Fjell et al., 2009). The young population also avoids as well the issue of aging-driven brain water content loss (Bansal et al., 2013) that affects image contrast and may influence cortical thickness measurements.

Multiscale analysis identifies the spatial scales at which sex differences manifest themselves. Isolating the scale at which we find differences or the lack thereof can help with confirming possible mechanisms of sex differences: e.g. an overall brain size difference without further relative differences on finer scales is consistent with a single-factor that may influence early development such as sex hormones or genetic sex differences. Also, multiscale analysis is important for proper interpretation of the results in cases where size differences are roughly similar across the cortex; e.g., it avoids claiming that some areas that are just above a statistical threshold show significant differences while others, just below threshold, do not. Rather, a multiscale (nested) analysis might rather suggest that there are sex differences at a coarse spatial scale but no further significant residual differences between areas at finer spatial scales.

The examination of sex differences faces an additional challenge mentioned previously: defining the appropriate scaling coefficients to correct for the overall difference in brain size of male and female subjects. Therefore, we briefly review the literature examining the relative size of brain structures in different mammalian species, and then empirically define the coefficients that best relate human cortical and subcortical structures to overall brain size when different metrics (e.g., cortical volume, area, and thickness) are used. Finally, we use the optimal scaling coefficients computed from a secondary dataset to characterize sex-related differences in brain structure that are independent of overall differences in brain size.

\section{Methods \\ Overview}

The anatomical images of 138 young, right-handed subjects were processed by FreeSurfer (http://surfer.nmr.mgh.harvard.edu), whose automated segmentation procedures also parcellated the cerebral cortical surface (Desikan et al., 2006) and subcortical structures (Fischl et al., 2002; Fischl et al., 2004). Interhemispheric asymmetries and sex differences in the cerebral cortex were examined using three cortical surface metrics: surface curvature bending energy, surface area, and cortical thickness. Differences in subcortical structure were evaluated with volume measures. Sex differences and sex by hemispheric interactions in cortical and subcortical structure were analyzed using male and female subjects carefully matched in both age and education.

\section{Subjects}

We studied the cortical and subcortical anatomy of 138 young subjects recruited from several colleges and military veteran sources in the northern California area, a cohort that we have used in a previous method manuscript (Kang et al., 2012). All subjects were right handed by self-report. There were 69 male and 69 female subjects, who were carefully matched in age (females: 18-38 years, mean 26.3 years; males: 18-38 years, mean 26.1 years) and education (approximately 15 years for both females and males). All subjects gave informed written consent following procedures approved by Institutional Review Board \#1 (IRB00000615; Federal Wide Assurance \#FWA00001687) of the Northern California Health Care System of the U.S. Department of Veterans Affairs. We also used an auxiliary group of high quality $\mathrm{T} 1$ images contained in a public repository, the OASIS dataset (http://www.oasis-brains.org; (Marcus et al., 2007)). This independent dataset was used to parameterize our volume normalizations using estimated intracranial volume as detailed below. In particular, we used a young, healthy subset of right-handed OASIS subjects containing 65 males (mean age 22.9; range 18-32) and 65 females (mean age 22.8, range 18-32) and processed them identically to images from our primary dataset. 


\section{Imaging}

Twohigh-resolution $\mathrm{T} 1$ anatomical images $(\mathrm{TR}=15 \mathrm{~ms}, \mathrm{TE}=4.47 \mathrm{~ms}$, Flip Angle $=35^{\circ}$, voxel size $0.94 \times 1.30 \times 0.94 \mathrm{~mm}$ ) were acquired on a $1.5 \mathrm{~T}$ Philips Eclipse scanner. These anatomical images were re-sampled to $1 \times 1 \times 1 \mathrm{~mm}$ resolution, averaged, segmented and then inflated to the cortical surface using FreeSurfer (Dale et al., 1999; Fischl et al., 1999a). The inflated cortical surfaces of the left hemisphere $(\mathrm{LH})$ and right hemisphere $(\mathrm{RH})$ were then coregistered to a spherical coordinate system (Fischl et al., 1999b). Figure 1A-D show the inflated cortical surfaces and spheres of LH averaged across all the 138 subjects. Six anatomical areas were identified (Kang et al., 2012) on the cortical surfaces based on the neuroanatomical parcellation (Desikan et al., 2006): Front Lobe (FL), Insular Cortex (IC), Limbic Cortex (LC), Occipital Lobe (OL), Parietal Lobe (PL) and Temporal Lobe (TL). The spherical view of the averaged LH was further projected to a flat map, as shown in Figure 1E, using Mollweide projection to visualize the entire 3D cortical surface in two dimensions (Kang et al., 2012).

FreeSurfer also provides the labels and statistical analysis of the segmented subcortical structures (Abe et al., 2010; Fischl et al.,
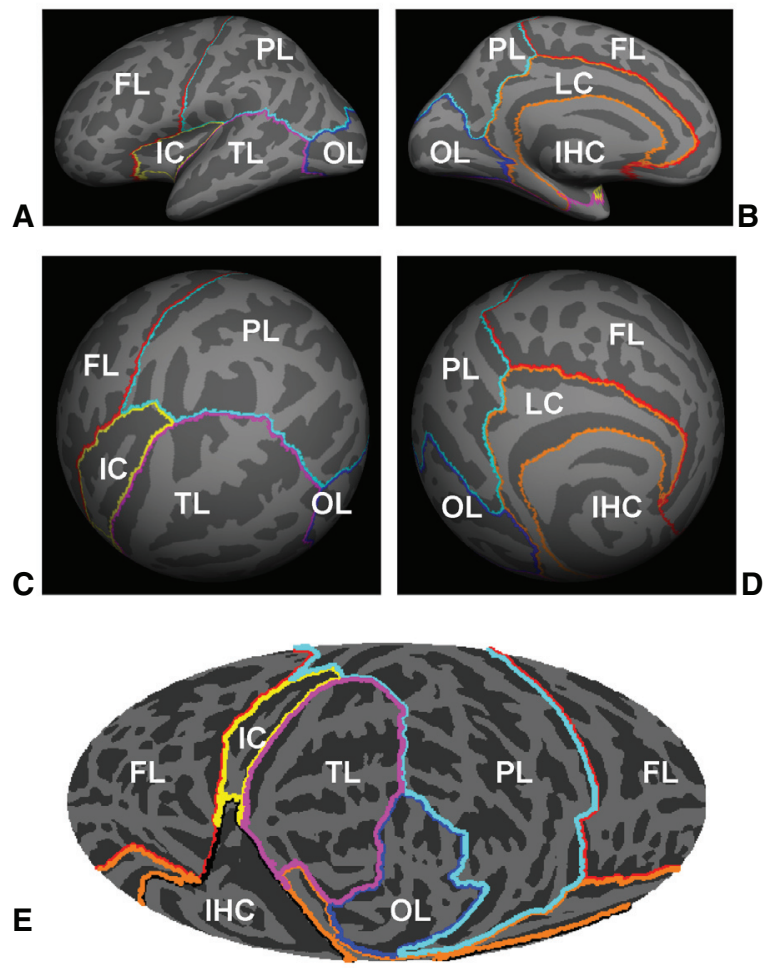

Figure 1. Inflation, spherical co-registration and projection of the cortical surface. Lateral $(\mathbf{A})$ and medial views $(\mathbf{B})$ of the inflated left hemisphere (LH) averaged across 138 subjects. (C) and (D) are the two views of the averaged sphere of LH when co-registered to the spherical coordinate system by FreeSurfer. (E) shows the Mollweide projection map of the averaged spherical surface of LH. The temporal and occipital lobes were positioned in the front/ central area of the map. Anatomical areas were shown by the color contours. FL: Front Lobe; IC: Insular Cortex; IHC: Inter-Hemispheric Connection; LC: Limbic Cortex; OL: Occipital Lobe; PL: Parietal Lobe; TL: Temporal Lobe.
2002; Fischl et al., 2004). Figure 2 shows the seven FreeSurfersegment subcortical structures discussed herein: i.e., the cerebellum, thalamus, caudate, putamen, pallidum, hippocampus, and amygdala.

Anatomical features on the cortical surface obtained in FreeSurfer, like surface curvature, bending energy, surface area, and cortical thickness, were extracted and resampled from each individual subject into the hemispherically unified coordinate system on the Mollweide projection map. Cortical surface bending energy is the areaweighted square of mean curvature after subtracting hemispheric average mean curvature. Bending energy better reflects the number of gyri and sulci in a region compared to other common cortical folding measures (Pienaar et al., 2008). Here we use the Bending Energy Density (BED), dividing out by the total area of a region, in order to use a quantity that is not highly correlated with surface area. The surface area associated with a vertex is the averaged area of all the triangles associated with that vertex on the surface (Fischl et al., 1999a). The total surface area of a region or hemisphere is the summation of the area of all vertices that it includes (Winkler et al., 2012). The above anatomical parameters for $\mathrm{LH}$ and RH were compared without correction for intra-cranial volume (ICV) or age. The volumes of the automatically segmented subcortical structures were also compared using linear regressions, with ICV as a covariate.

\section{Volume normalization}

Several methods have previously been used to normalize gray matter volume results for both cortical and subcortical structures, most commonly either by using simple normalization (division) by a total brain volume, or by normalizing brain volumes in stereotaxic (MNI or Talairach) space. However, it is well-established that gray matter scales sublinearly, and white matter (WM) supralinearly,

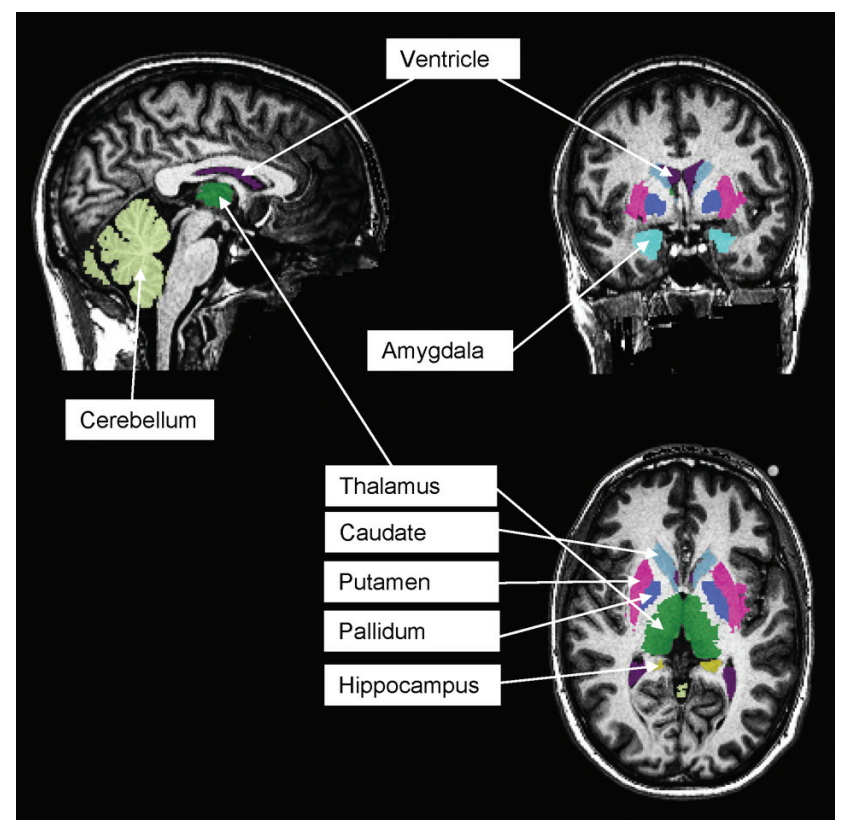

Figure 2. Segmentation of subcortical structures for a subject by FreeSurfer. The labels indicate the structures on the right hemisphere. 
with respect to overall cranial or brain volume across mammals in general (Zhang \& Sejnowski, 2000), and across primates in particular (Herculano-Houzel et al., 2010; Ventura-Antunes et al., 2013). Because the relationship between ICV and size may vary from structure to structure (Bush \& Allman, 2003), more sophistical scaling is required (Im et al., 2008). Therefore, we used the auxiliary OASIS dataset to establish the fractional powers by which subcortical gray matter structures (e.g. putamen, amygdala, etc.) and total cortical area and thickness vary with respect to total ICV, as computed using FreeSurfer (Buckner et al., 2004). This was accomplished by using linear regression over logarithmically transformed ICV and log-transformed structure volumes (or cortical area or thickness). ICV to the estimated power was then used as a covariate within subsequent normalized regression analyses to examine sex differences.

\section{Sex differences}

The sex differences of the cortical surface parameters and the volumes of the subcortical structures were analyzed both without ICV correction and with ICV correction using empirically optimized regression coefficients. We compared our data to published results (Leonard et al., 2008; Li et al., 2014; Luders et al., 2004; Luders et al., 2006; Ruigrok et al., 2014; Sowell et al., 2007). Unlike most previous studies, the male and female subgroups were balanced in age and education.

\section{Statistical analyses}

Multivariate linear regression (using R's $l m$ function v. 2.15.3 and mle4 library: r-project.org) over sex, age, ICV and a dependent variable of overall subcortical structure volume or cortical area/thickness/bending, either hemispherically averaged or differenced, were used to analyze overall sex and hemispheric differences. Purely categorical within-subject factors were analyzed using repeated measures ANOVA (using CLEAVE: www.ebire.org/hcnlab) with Geisser-Greenhouse non-sphericity corrections uniformly applied. Correlations were computed using MATLAB (v7.14) statistics toolbox (www.mathworks.com), with Pearson correlations used to analyze pairwise relationships and with partial correlations to control for covariates. Because we were looking simultaneously at many effects, we adjusted statistical thresholds so that $\mathrm{p}<0.01$ would indicate a trend, $\mathrm{p}<0.001$ weak statistical significance, and $\mathrm{p}<0.0001$ to indicate a strong statistical relationship. We also report effect size estimates $(\eta)$ in ANOVA results, and regression coefficients to clarify effect magnitude.

\section{Results}

The results are presented as follows: we first give a whole-cortex overview of how our anatomical quantities are related to each other and to the relevant demographic variables. Next, we characterize how ICV is best related to anatomical quantities as well as test ICV's relationship to local cortical asymmetry. Then we record the sex difference results for the whole cortex, cortical regions, and subcortical anatomical structures.

\section{Dataset 1. Raw Data}

http://dx.doi.org/10.5256/f1000research.6210.d44689

Raw data for cortical and subcortical dimension calculations. Descriptions for individual files can be found in 'readme for data. docx'.

\section{Whole-cortex anatomical relationships}

We characterized the relationships between whole cortex area, thickness, and BED mean values using full partial Pearson correlations, i.e. pairwise correlations factoring out all other considered quantities. In addition to relating age, sex, and ICV to mean area, thickness, and BED, we also add the three quantities of mean left hemisphere minus mean right hemisphere area, thickness, and BED for concurrent consideration. The most significant of the Bonferroni-corrected partial correlations was found between ICV and mean area $(\mathrm{r}=+0.89, \mathrm{p}<0.0001)$. The second most significant global correlation was between ICV and mean BED ( $r=-0.39$, $\mathrm{p}<0.0001$ ), reflecting the constraint that smaller topologically spherical 2D surfaces must have greater mean bending than do larger ones. A slightly weaker positive partial correlation $(r=+0.36$, $\mathrm{p}<0.0001$ ) was found between mean cortical area and mean BED. This makes sense as greater cortical area (with ICV held constant) requires greater cortical folding. The weakest partial correlation of significance $(\mathrm{r}=-0.31, \mathrm{p}<0.001)$, was found between areal and thickness asymmetries. We do not know if this negative correlation reflects a true tradeoff in cortical volume configuration or is an artifact of FreeSurfer's estimation methods, e.g. that FreeSurfer's delineation of the WM/GM boundary is used in estimating both surface area and cortical thickness.

Two additional trend-level cortical relationships were found. Mean thickness (holding ICV and area constant) correlated negatively with BED $(r=-0.29, p<0.01)$, i.e. greater thickness was associated with less cortical folding, implying that thicker cortex has fewer folds within a given volume. We also found a weak relationship between age and mean cortical thickness $(\mathrm{r}=-0.29, \mathrm{p}<0.01)$ which is not surprising, even within this young-adult cohort. We obtained similar whole-cortex results using the OASIS dataset as well (Supplemental Table S3).

\section{Corrections for intracortical volume}

Table 2 shows the estimated exponent $\beta$ of ICV that correlated best with our measured size quantities $Q$, using the model $Q=\alpha \times I C V^{\beta}$ with the auxiliary OASIS dataset and employing the current dataset for comparison. All subcortical volumes had sublinear relationships with ICV $(\beta<1)$. However, of cortical quantities only area had a substantial positive, but still sublinear relationship with ICV. Moreover, cortical thickness as measured by FreeSurfer was uninfluenced by brain size. Thus, typical methods of normalizing gray matter volumes based on linear ICV correction would significantly overcorrect cortical values, especially for thickness. 
Table 2. Estimated optimal ICV power values for brain structures. Powers of intracranial volume (ICV) estimated to correlate best with volume (subcortical) and cortical area and thickness quantities. All log-log regressions are significant $\mathrm{p}<0.0001$ except for thickness and bending energy density (BED). Results are shown with 95\% confidence intervals for the primary (right column) and OASIS (left column) datasets.

\begin{tabular}{|l|c|c|}
\hline & $\begin{array}{c}\text { OASIS-130 } \\
\text { Dataset }\end{array}$ & $\begin{array}{c}\text { Current-138 } \\
\text { Dataset }\end{array}$ \\
\hline Cerebellum & $0.70 \pm 0.14$ & $0.83 \pm 0.12$ \\
\hline Thalamus & $0.77 \pm 0.15$ & $0.77 \pm 0.11$ \\
\hline Caudate & $0.82 \pm 0.17$ & $0.87 \pm 0.16$ \\
\hline Putamen & $0.72 \pm 0.15$ & $0.67 \pm 0.15$ \\
\hline Pallidum & $0.76 \pm 0.16$ & $0.79 \pm 0.16$ \\
\hline Hippocampus & $0.61 \pm 0.13$ & $0.56 \pm 0.10$ \\
\hline Amygdala & $0.75 \pm 0.17$ & $0.69 \pm 0.16$ \\
\hline Cortical Area & $0.87 \pm 0.06$ & $0.84 \pm 0.07$ \\
\hline Cortical Thickness & $-0.01 \pm 0.06$ & $0.02 \pm 0.07$ \\
\hline Cortical BED & $-0.07 \pm 0.07$ & $-0.09 \pm 0.08$ \\
\hline
\end{tabular}

Whole hemisphere sex differences in cortical thickness, area, and folding

We first describe the results of regression over the demographic variables of sex and age for thickness, BED, and area, averaged across the entire cortex of both hemispheres. The independent variable age failed to reach significance in any of the three regressions, with the highest significance being in the thickness regression with anestimated loss of thickness of $0.004 \mathrm{~mm} / \mathrm{yr}\left(\mathrm{t}_{135}=2.4\right.$, $\mathrm{p}=0.017$ ). Sex also did not impact mean cortical thickness or mean BED. However, as expected from previous studies, sex correlated strongly with mean area: men had $10.4 \%\left(93 \mathrm{~cm}^{2}\right)$ more area than women $\left(\mathrm{t}_{135}=7.9, \mathrm{p}<0.0001\right)$, similar to their $10.2 \%$ increase in ICV $\left(157 \mathrm{~cm}^{3}\right)\left[\mathrm{t}_{136}=7.1, \mathrm{p}<0.0001\right]$.
However, when ICV ${ }^{0.87}$, the strongest predictor of cortical area $\left(\mathrm{t}_{134}=17.8, \mathrm{p}<0.0001 ; \alpha=1.33\left[\mathrm{ICV} \mathrm{cm}{ }^{3}\right.\right.$, area $\left.\left.\mathrm{cm}^{2}\right]\right)$, was added to the analysis, the omnibus sex effect was reduced to a trend $\left(\mathrm{t}_{134}=3.0\right.$, $\mathrm{p}<0.01$; males $+2.8 \%\left(23 \mathrm{~cm}^{2}\right)$ greater than females). We also regressed the overall mean differences between the left and right hemispheres in thickness and area over the factors sex, age, and combined mean thickness, area, or BED as independent variables (and for area, also $\mathrm{ICV}^{0.87}$ ). The only trend to be found in those three regressions was that subjects with larger ICVs tended to show a small increase in relative left hemisphere cortical area $\left(\mathrm{t}_{134}=2.6, \mathrm{p}=0.01\right.$; every $+10 \%$ ICV change implies a $+0.7 \%$ LH area change).

\section{Sex differences in cortical structures}

We used ANOVAs with sex, lobe, and parcel factors to look for regional cortical differences between men and women. We used ICV corrected area for all area comparisons, using the estimated $\mathrm{ICV}^{0.87}$ parameter from Table 2. This assumes that the ICV exponent applies across the entire cortex (Im et al., 2008), a stance which has some support from cortical area genetic heritability studies (Eyler et al., 2011) (see also Supplementary Table S2).

There were no clear sex differences in regional BED or cortical thickness. BED values did not differ between men and women at the lobar level, with the maximum difference found in the occipital lobe $\left(\mathrm{F}_{1,136}=4.1, \mathrm{p}>0.01\right)$. Nor were there significant parcel level differences $\left(\mathrm{p}<10^{-6}\right)$ in BED. For thickness, the only lobar trend was found in the limbic cortex, where females had $0.05 \mathrm{~mm}$ thicker cortex $\left(\mathrm{F}_{1,136}=7.1, \mathrm{p}<0.01, \eta=0.05\right)$.

In contrast, significant sex differences were found in ICV-corrected area measures as shown in Figure 3. As might be expected given the fact that males had greater overall area, even after adjusting for ICV, males had modestly significant greater area in the frontal lobe $\left(+3.3 \%, \mathrm{~F}_{1,136}=13.6, \mathrm{p}<0.001, \eta=0.09\right)$, and a trend toward greater area in the occipital lobe $\left(+3.8 \%, \mathrm{~F}_{1,136}=7.2, \mathrm{p}<0.01, \eta=0.05\right)$, and the temporal lobe $\left(+2.4 \%, \mathrm{~F}_{1,136}=7.1, \mathrm{p}<0.01, \eta=0.05\right)$. There were no residual sex differences at the parcel level in any lobe, and this result held even when the $\mathrm{p}$ value was lowered to trend levels $\left(\mathrm{p}<10^{-4}\right)$.
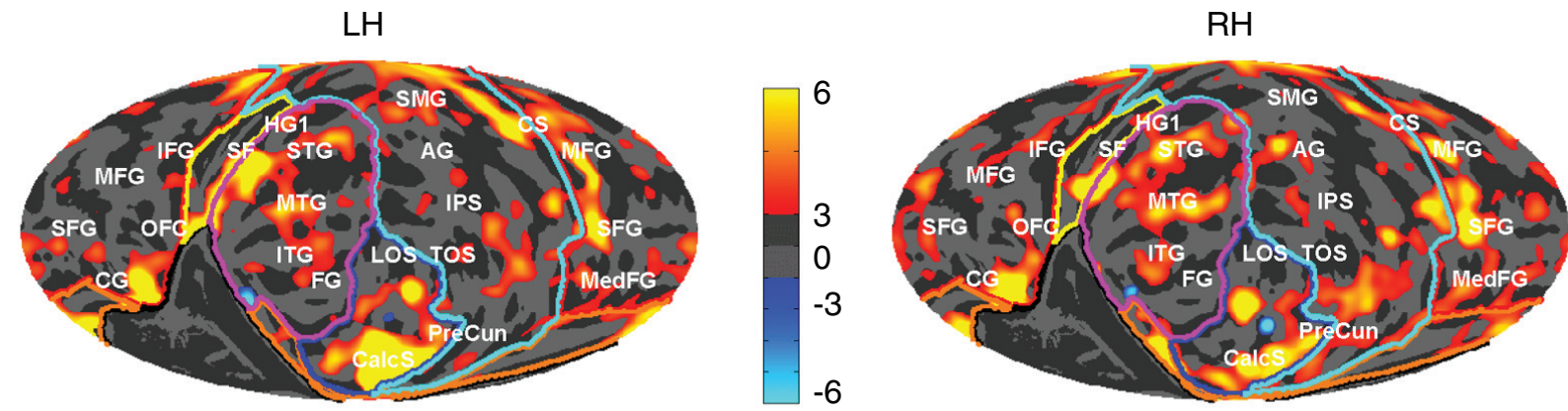

Figure 3. Male vs. female ICV-adjusted mean area percentage differences on the cortex. Red areas indicate males $>$ females (\%) and blue females > males, ICV adjusted. Gyral and sulcal structures are shown by the light and dark gray in the background. LH left hemisphere, $\mathrm{RH}$ right. Anatomical structures (white labels): AG, angular gyrus; CG, cingulate gyrus; CalcS, calcarine sulcus; CS, central sulcus; FG, fusiform gyrus; HG, Heschl's gyrus; IFG, inferior frontal gyrus; IPS, intraparietal sulcus; ITG, inferior temporal gyrus; LOS, lateral occipital sulcus; MedFG, medial frontal gyrus; MFG, mid-frontal gyrus, MTG, middle temporal gyrus; OFC, orbitofrontal cortex; PreCun, precuneus; SF, Sylvian fissure; SFG, superior frontal gyrus; SMG, supramarginal gyrus; SPL, superior parietal lobule; STG, superior temporal gyrus; TOS, transverse occipital sulcus. 
Overall (Figure 3) the corrected area differences across the sexes appeared to be symmetric, though there was a trend in the hemisphere $\times$ temporal lobe interaction with sex $(\operatorname{Sex} \times$ Hemi $\times$ Parcel, $\mathrm{F}_{6,816}=3.3, \mathrm{p}=0.015, \eta=0.02$ ) that might support lateral temporal areal asymmetries specific to just one sex. Finally, we saw no significant sex by hemisphere interactions in any parcel in any lobe in thickness, area or BED.

\section{Sex differences in subcortical structures}

The ANOVA in Table 3 also shows that males had 3-6\% larger subcortical volumes on average than did females $(\eta=0.12$ to 0.30$)$; i.e., an increase substantially less than the sex difference in ICV. Table 3 also records the results of linear regression analyses using ICV as a covariate (with exponents shown in Table 2) to identify sex differences not accounted for by overall brain size. With ICV corrections, only the amygdala remained substantially relatively larger in men $(4.0 \%)$ though there was also a trend for the male cerebellum to be larger (1.8\%) as well. Finally, Table 3 shows that in this uniformly young subject group, there was little detectable volume loss likely due to age, with trends seen only in the cerebellum $(-0.3 \% / \mathrm{yr})$ and the putamen $(-0.4 \% / \mathrm{yr})$.

\section{Discussion}

\section{Gray matter normalization}

It is clear from Table 2 that gray matter in both the cerebral cortex and major subcortical structures increases sublinearly with respect to intracortical volume (ICV). Supplementary Table S1 and Supplementary Table S2 show that in addition, both sexes generally have similar estimated ICV exponents, although the appropriate exponent to use with cortical surface area may vary from lobe to lobe (we used a fixed exponent above). These facts reaffirm that the use of affine normalized brains or the use of simple ICV-based normalization overestimate gray matter volumes for subjects with smaller ICVs, e.g. in females as a group (Im et al., 2008). This is particularly true for cortical thickness which is well-conserved across different mammalian species (Karbowski, 2014); e.g., ranging from $0.8 \mathrm{~mm}$ in the mouse to $3.0 \mathrm{~mm}$ in the elephant, consistent with an ICV exponent of approximately 0.1 (Zhang \& Sejnowski, 2000).

A previous study found ICV exponents relating to thickness of 0.24 and to area of 0.74 (Im et al., 2008). The lack of correlation of ICV with thickness in our results might be due to FreeSurfer's conservative method for measuring thickness using minimum distances from pial to WM/GM junction surfaces, or might reflect the fact that our magnetic resonance imaging (MRI) resolution of $\sim 1.0 \mathrm{~mm}$ was small compared to the mean human cortical thickness of $2.5 \mathrm{~mm}$. On the other hand the estimate of Im et al. (2008) of 0.24 estimated with the CIVET automated surface rendering/ measurement tool is likely too high: a separate estimate in that same study showed that cortical GM volume correlated best with $\mathrm{ICV}^{0.85}$. Given that Im et al.'s regressions for volume and area with ICV were much more reliable (as are ours) than those for thickness (Im et al., 2008), and assuming that volume roughly equals thickness times area, the optimal exponent for correlating ICV with thickness should have been much closer to 0.1 (i.e., 0.85 minus 0.74). Thus, it may be that current MR imaging or thickness estimation tools lack adequate precision for estimating proper thickness to ICV relationships within humans.

\section{Cortical sex differences}

With the exception of the well-known differences in overall cortical surface area (Luders \& Toga, 2010), intracranial volume (Ruigrok et al., 2014) and to a lesser extent subcortical volumes (Li et al., 2014), sex differences were generally small in the current study. The sex difference of $10 \%$ in cortical surface area that we found was similar to the results of most recent MRI studies (Im et al., 2008; Nopoulos et al., 2000; Pakkenberg \& Gundersen, 1997; Ropele et al., 2009; Ruigrok et al., 2014; Van Essen et al., 2012) and post-mortem results (Pakkenberg \& Gundersen, 1997), but is

\begin{tabular}{|c|c|c|c|c|}
\hline & Age & $\mathrm{ICV}^{\alpha}$ & $\operatorname{Sex}(M-F)$ & Sex ANOVA \\
\hline Cerebellum & $\begin{array}{l}t_{134}=-2.8^{\star} \\
-0.3 \% / y r\end{array}$ & $t_{134}=+10.8^{\star \star \star}$ & $\begin{array}{l}t_{134}=+2.8^{*} \\
+1.8 \% \text { Males }\end{array}$ & $\begin{array}{l}t_{136}=+7.2^{\star \star \star} \\
+5.5 \% \text { Males }\end{array}$ \\
\hline Thalamus & $t_{134}=-0.5$ & $t_{134}=+11.8^{\star \star \star}$ & $t_{134}=+0.0$ & $\begin{array}{l}t_{136}=+5.1^{* * *} \\
+4.0 \% \text { Males }\end{array}$ \\
\hline Caudate & $t_{134}=-0.8$ & $t_{134}=+8.9^{\star \star *}$ & $t_{134}=+0.4$ & $\begin{array}{l}t_{136}=+4.7^{\star \star \star} \\
+4.7 \% \text { Males }\end{array}$ \\
\hline Putamen & $\begin{array}{l}t_{134}=-3.1^{*} \\
-0.4 \% / y r\end{array}$ & $t_{134}=+6.8^{\star \star \star}$ & $t_{134}=+2.4$ & $\begin{array}{l}t_{136}=+5.9^{\star \star \star} \\
+4.8 \% \text { Males }\end{array}$ \\
\hline Pallidum & $t_{134}=-2.1$ & $t_{134}=+7.7^{\star \star \star}$ & $t_{134}=+1.4$ & $\begin{array}{l}t_{136}=+5.3^{\star \star \star} \\
+5.0 \% \text { Males }\end{array}$ \\
\hline Hippocampus & $t_{134}=+0.5$ & $t_{134}=+9.3^{\star \star *}$ & $t_{134}=-0.2$ & $\begin{array}{l}t_{136}=+4.2^{\star \star \star} \\
+2.7 \% \text { Males }\end{array}$ \\
\hline Amygdala & $t_{134}=-0.8$ & $\mathrm{t}_{134}=+5.1^{\star \star *}$ & $\begin{array}{l}t_{134}=+4.4^{\star \star \star} \\
+4.0 \% \text { Males }\end{array}$ & $\begin{array}{l}t_{136}=+7.7^{\star \star \star} \\
+6.3 \% \text { Males }\end{array}$ \\
\hline
\end{tabular}


somewhat greater than the areal differences reported by others (Acer et al., 2010; Barta \& Dazzan, 2003; Ronan et al., 2006; Salat et al., 2004). When we adjust overall cortical surface area for ICV, males had modest but significantly greater surface area, particularly in the frontal lobe. In order to confirm this result, we did a follow up analysis of a subset of our subject group consisting of 43 pairs of men and women matched for ICV, as was done by Luders et al. (2009). We found the same small difference in surface area $\left(\mathrm{F}_{1,42}=7.5, \mathrm{p}=0.009,2.5 \% \mathrm{M}>\mathrm{F}, \eta=0.15\right)$ plus an even weaker, opposite one in thickness $\left(\mathrm{F}_{1,42}=4.0, \mathrm{p}=0.05,1.5 \% \mathrm{~F}>\mathrm{M}, \eta=0.09\right)$ and none in $\operatorname{BED}\left(\mathrm{F}_{1,42}=0.5, \mathrm{p}=0.50\right)$ between men and women (see also Supplementary Table S5). Thus, the ICV adjustment of area appears to be unbiased with respect to our data when used to analyze relative sex differences in this moderate brain sized subgroup.

The effect sizes for other significant sex-related differences were small $(\eta<0.1)$. The only lobar level thickness difference we found was a trend for females having greater limbic cortex values. Such a result is consistent with observations that the entire limbic cortex contains many estrogen/androgen receptors during development (Goldstein et al., 2001). In fact, when 33 cortical parcels are ranked as having either a high or low density in estrogen and androgen receptors during early development (Goldstein et al., 2001), there was a significant relationship to those Desikan parcels having significant ( $\mathrm{t}$ score) percentile thickness (but not area) advantages favoring females across our 138 subjects [Thickness: ANOVA $F_{1,32}=10.8$, $\mathrm{p}<0.01, \eta=0.25$; Area: $\mathrm{F}_{1,32}=0.3$, n.s.]. Thus, though regional sex differences in thickness are small, the overall pattern appears to support a classic sex steroid mechanism for cortical thickness (but not area) differentiation.

On the other side, males had small relative areal advantages, even after ICV correction, in the frontal and occipital lobes, as well as in patchy regions of the temporal and parietal lobes. In particular, we failed to find evidence of sex differences in volume favoring females in either the parietal or occipital lobes as reported in several recent studies (Im et al., 2006; Luders et al., 2006; Lv et al., 2010; Savic \& Arver, 2014). Overall, the sex differences that we observed were much smaller in magnitude and effect size than those of hemispheric asymmetries (Supplemental Table S5; Kang et al., 2015). However, when we take the overall pattern of parcel level area differences between the sexes, and correlate them with genetic heritability estimates taken from imaging studies of family members (Winkler et al., 2010), then we find that there was a significant relationship to those parcels having significant ( $\mathrm{t}$ score) percentile area (but not thickness) advantages favoring males across our 138 subjects [Area: Pearson $\mathrm{r}=-0.33, \mathrm{p}<0.05$; Thickness: $\mathrm{r}=0.07$, n.s.]. Thus, a genetic explanation for the pattern of small regional area asymmetries is indicated here [for the OASIS data the heritability/ area difference Pearson correlation was $\mathrm{r}=-0.52]$.

Overall, we found few significant regional sex differences in cortical thickness, consistent with some recent reports (Fjell et al., 2009; Im et al., 2006; Im et al., 2008) but not others (Im et al., 2010; Luders et al., 2006; Sowell et al., 2007). The larger differences reported by others may reflect uncontrolled factors, e.g., age, handedness, or education, that were controlled in the current study. This underscores the importance of using appropriate regression functions for ICV correction (Im et al., 2008). It is also possible, however, that the two sexes in our relatively well-educated group may be more homogeneous than in a broader community sample of young adults (Luders \& Toga, 2010) or in other non-western populations.

Importantly, the well-established sex difference of $8-10 \%$ in cortical volume (Peters et al., 1998; Ruigrok et al., 2014) appears to be almost completely attributable to differences in surface area, as one might expect if sex differences follow the scaling relationships between brain area and cortical thickness seen in mammalian brains (Toro et al., 2008). In this sense our sex difference results resemble those of researchers (Brun et al., 2009; Im et al., 2008; Leonard et al., 2008) who found that individual differences in overall brain size explain far more variance in brain anatomy than do residual differences due to sex.

\section{Subcortical sex differences}

When considering subcortical sex differences, a recent study using similar FreeSurfer methodology (Li et al., 2014) found, as we did, that all female subcortical structures were smaller on average than corresponding male ones. When normalized linearly by total brain volume, Li et al. found that the hippocampus of females was relatively larger than that of males. However, simple normalization using total brain volume or ICV would overcompensate for relative hippocampal volumes, especially as the hippocampus has the smallest ICV exponent (Table 2). We found no significant normalized volume sex differences in the hippocampus.

Using optimized exponents for ICV, we found significant differences in the volumes of the amygdala and the cerebellum between males and females (Table 3), consistent with most previous studies (Bramen et al., 2011; Kim et al., 2012; Neufang et al., 2009; Peper et al., 2009). However, one issue with the amygdala sex difference is that the fractional ICV scaling adjustment was the least well-fitting of any subcortical structure when estimated from the OASIS data, perhaps stemming from a difference in scaling relations between the two sexes in our dataset (see Supplemental Table S1). Nevertheless, we obtained a significant sex difference in the amygdala when we analyzed the subcortical volumes of the OASIS-130 dataset (Supplementary Table S4) and also when we analyzed the 43 ICV-matched pairs (male-female) subset of the primary dataset $\left(\mathrm{F}_{1,42}=12.9, \mathrm{p}=0.0009, \mathrm{M}>\mathrm{F} 7.3 \%\right)$ using no brain-size covariate. Finally, we note that there have been measurements (Lentini et al., 2013; Neufang et al., 2009) showing that testosterone levels in adolescents and adults track the size of the amygdala (and the hippocampus, but not the basal ganglia), suggesting an important role of sex steroids in the development of the amygdala.

\section{Conclusions}

After appropriately correcting for the large, intracranial volumerelated overall differences in the cortical surface area and subcortical structure size between male and female subjects, cortical and subcortical sex differences were reduced in magnitude and generally showed small effect sizes. Males had larger amygdala after ICV volume correction, and there were subtle differences in some cortical regions as well, with relative omnibus area differences favoring males and thickness differences favoring females. The regional distribution of cortical morphometric sex differences also 
indicated being related to genetic and developmental processes of brain growth.

Our emphasis on the use of mammalian brain scaling in looking at sex differences echoes the suggestion of Im et al. (2008) and extends it to subcortical structures. This avoids the overcorrections of area, volume and especially thickness values that have, we believe, in the past produced results improperly assigning larger relative regional areas, volumes and thicknesses to female subjects. Also, we also repeat Im et al.'s (2008) call to avoid using VBM for investigating group differences when groups have sizeable mean ICV differences because a larger mammalian brain is not an affinescaled smaller mammalian brain: the WM/GM ratio is larger in the former and cortical volume differences are not evenly distributed geometrically; i.e., volume increases are overwhelmingly increases in area resulting in more folding. Lastly, we endorse the empiricallyderived recommendations of Barnes et al. (2010) to use ICV as a covariate when comparing cortical area measures but not when comparing thicknesses.

\section{Data availability}

F1000Research: Dataset 1. Raw Data, 10.5256/f1000research. 6210.44689 (Herron et al., 2015).

Neither our IRB-approved MRI imaging protocol nor our informed consent document signed by our subjects permit us to make the original T1 MRI images publically available. However, we do provide all extracted, anonymized subject data used in the above statistical analyses as well as for the corresponding OASIS data subset that we used.

The androgen/estrogen receptor density level data referred to in the Discussion section from (Goldstein et al., 2001) was taken from Table 2. Only cortical values were used.
The heritability $\left(\mathrm{h}^{2}\right)$ estimates referred to in the Discussion section were taken from Table 3 in (Winkler et al., 2010).

\section{Consent}

All subjects provided informed written consent following procedures approved by the Institutional Review Board of the Northern California Health Care System of the Department of Veterans Affairs.

\section{Author contributions}

DLW, XK, and TJH designed the study. XK collected the imaging data. TJH and XK developed the statistical analyses. XK wrote the first draft of the manuscript. All authors were involved in the revision of the draft manuscript and have agreed to its final content.

\section{Competing interests}

No competing interests were disclosed.

\section{Grant information}

This research was supported by a VA Research and Development Grants CX000583 and CX001000 to DLW. The content is solely the responsibility of the authors and does not necessarily represent the official views of Department of Veterans Affairs or the U.S. Government.

I confirm that the funders had no role in study design, data collection and analysis, decision to publish, or preparation of the manuscript.

\section{Acknowledgements}

We thank Bill Yund and the Radiology Service at the Martinez VA Clinic for help in collecting the imaging data. We also thank Marc Ettlinger for helpful comments.

\section{Supplementary material}

Table S1. Powers of ICV estimated to regress best with subcortical structure volume or cortical area/thickness for each sex separately. No significant sex differences found except with the Current-138 dataset's amygdala $(p<0.05)$. However we note that in subcortical volumes the female exponents are always bigger except in the OASIS cerebellum (12 of 13 ( 1 tie), $p<0.01$ sign test, post-hoc).

\begin{tabular}{|l|l|l|l|l|}
\hline & $\begin{array}{l}\text { OASIS-130 } \\
\text { Males }\end{array}$ & $\begin{array}{l}\text { OASIS-130 } \\
\text { Females }\end{array}$ & $\begin{array}{l}\text { Current-138 } \\
\text { Males }\end{array}$ & $\begin{array}{l}\text { Current-138 } \\
\text { Females }\end{array}$ \\
\hline Cerebellum & 0.65 & 0.59 & 0.81 & 0.87 \\
\hline Thalamus & 0.68 & 0.73 & 0.77 & 0.77 \\
\hline Caudate & 0.77 & 0.87 & 0.86 & 0.88 \\
\hline Putamen & 0.62 & 0.70 & 0.58 & 0.77 \\
\hline Pallidum & 0.61 & 0.68 & 0.74 & 0.85 \\
\hline Hippocampus & 0.57 & 0.66 & 0.54 & 0.58 \\
\hline Amygdala & 0.60 & 0.61 & 0.58 & 0.83 \\
\hline Cortical Area & 0.86 & 0.84 & 0.86 & 0.81 \\
\hline Cortical Thickness & 0.03 & 0.00 & 0.00 & 0.04 \\
\hline
\end{tabular}


Table S2. Exponents of ICV such that ICV ${ }^{\alpha}$ correlates best with mean subject cortical area values in each of 6 lobes. Mean \pm Standard Deviation. The limbic lobe is the only one showing a difference in estimated exponents between the two datasets, and the insula is the only lobe showing a seemingly reliable different (lower) exponent than the rest of the lobes in both hemispheres.

\begin{tabular}{|l|l|l|}
\hline & Current-138 Data & OASIS-130 Data \\
\hline Frontal Lobe & $\alpha=0.91 \pm 0.05$ & $\alpha=0.86 \pm 0.04$ \\
\hline Insula & $\alpha=0.72 \pm 0.06$ & $\alpha=0.71 \pm 0.05$ \\
\hline Limbic Lobe & $\alpha=0.73 \pm 0.06$ & $\alpha=0.96 \pm 0.05$ \\
\hline Occipital Lobe & $\alpha=0.85 \pm 0.08$ & $\alpha=0.91 \pm 0.08$ \\
\hline Parietal Lobe & $\alpha=0.79 \pm 0.05$ & $\alpha=0.82 \pm 0.04$ \\
\hline Temporal Lobe & $\alpha=0.84 \pm 0.05$ & $\alpha=0.91 \pm 0.04$ \\
\hline
\end{tabular}

Table S3. Significant Pearson full partial correlations of area (hemispheric mean and difference); thickness (hemispheric mean and difference); and age, sex, and ICV ${ }^{0.84}$ over the OASIS-130 data.

1) ICV and mean area: $r=+0.90$

2) Age and mean thickness: $r=-0.46$

3) Mean thickness and mean area: $r=-0.34$

4) ICV and mean thickness: $r=+0.29$ - more like (Zhang \& Sejnowski, 2000).

There were no significant sex vs. mean area or area asymmetry vs. thickness asymmetry

Table S4. Subcortical volume regression results applied to the OASIS-130 data from two analyses for each of seven structures. The multifactorial regression's dependent variable was structure mean volume across hemispheres; with age and sex as factors as well as ICV - to the power estimated in Table 1 (right column) - as an independent variable to see how much overall brain size reduce sex differences. An ANOVA over sex (rightmost column) was used to identify unadjusted factors contributing to volume values. ${ }^{*} p<0.01$, ${ }^{* *} p<0.001,{ }^{* *} p<0.0001$, Bonferroni corrected. Significant results in boldface.

\begin{tabular}{|c|c|c|c|c|}
\hline & Age & $\mathrm{ICV}^{\alpha}$ & Sex (M-F) & Sex ANOVA \\
\hline Cerebellum & $t_{126}=-2.4$ & $t_{126}=+7.3^{\star \star \star}$ & $t_{126}=+2.2$ & $\begin{array}{l}t_{128}=+5.9^{\star \star \star} \\
+9.5 \% \text { Males }\end{array}$ \\
\hline Thalamus & $t_{126}=+0.1$ & $t_{126}=+11.6^{\star \star *}$ & $t_{126}=+2.0$ & $\begin{array}{l}t_{136}=+6.8^{* * *} \\
+9.6 \% \text { Males }\end{array}$ \\
\hline Caudate & $\begin{array}{l}t_{126}=-3.3^{*} \\
-0.8 \% / y r\end{array}$ & $t_{126}=+7.3^{\star \star \star}$ & $t_{126}=+0.3$ & $\begin{array}{l}t_{128}=+3.9^{\star *} \\
+8.1 \% \text { Males }\end{array}$ \\
\hline Putamen & $\begin{array}{l}t_{126}=-3.6^{\star *} \\
-0.7 \% / y r\end{array}$ & $t_{126}=+7.1^{\star \star \star}$ & $t_{126}=+1.5$ & $\begin{array}{l}t_{128}=+5.0^{* \star *} \\
+8.5 \% \text { Males }\end{array}$ \\
\hline Pallidum & $\begin{array}{l}t_{126}=-3.5^{\star *} \\
-0.8 \% / y r\end{array}$ & $t_{126}=+6.4^{\star \star \star}$ & $\begin{array}{l}t_{126}=+2.7^{*} \\
+2.2 \% \text { Males }\end{array}$ & $\begin{array}{l}t_{128}=+6.0^{* * *} \\
+10.4 \% \text { Males }\end{array}$ \\
\hline Hippocampus & $t_{126}=-1.2$ & $\mathrm{t}_{126}=+7.3^{\star \star \star}$ & $t_{134}=-0.0$ & $\begin{array}{l}t_{128}=+3.9^{* *} \\
+6.1 \% \text { Males }\end{array}$ \\
\hline Amygdala & $t_{126}=-0.7$ & $t_{126}=+5.9^{\star \star \star}$ & $\begin{array}{l}t_{126}=+2.8^{*} \\
+2.6 \% \text { Males }\end{array}$ & $\begin{array}{l}t_{128}=+6.3^{\star \star *} \\
+11.4 \% \text { Males }\end{array}$ \\
\hline
\end{tabular}


Table S5. Matched-pair analysis of significant Desikan parcel-level sex and hemisphere differences of area, thickness, and BED. 43 ICV-matched male-female pairs of subjects from the current-138 group were selected. ICV differences between the 43 matched pairs averaged $0.31 \%$. Area sex and hemisphere differences are not adjusted for ICV and are analyzed using repeated measures ANOVA for sex as well as hemisphere. Significance is at $p<0.01$ Bonferroni corrected for all $34 \times 3 \times 3$ comparisons. The asymmetric parcels are similar to those found in all 138 subjects (see Kang et al., 2015) and provide contrast to the complete lack of localizable, significant parcel-level sex differences (all p >0.07, corrected) or sex interactions.

\begin{tabular}{|c|c|c|c|}
\hline & Thickness (mm) & Area $\left(\mathrm{cm}^{2}\right)$ & BED \\
\hline Sex & - & - & - \\
\hline Hemisphere & $\begin{array}{l}\text { Lateral Occipital RH>LH by } 4 \% \\
\text { Transverse Temporal RH>LH by } 5 \%\end{array}$ & $\begin{array}{l}\text { Caudal Anterior Cingulate RH>LH by } 19 \% \\
\text { Caudal Mid Frontal LH>RH by } 11 \% \\
\text { Inferior Parietal } \mathrm{RH}>\mathrm{LH} \text { by } 19 \% \\
\text { Middle Temporal } \mathrm{RH}>\mathrm{LH} \text { by } 10 \% \\
\text { Paracentral } \mathrm{RH}>\mathrm{LH} \text { by } 13 \% \\
\text { Pars Opercularis } \mathrm{LH}>\mathrm{RH} \text { by } 17 \% \\
\text { Pars Orbitalis } \mathrm{RH}>\mathrm{LH} \text { by } 18 \% \\
\text { Pars Triangularis RH>LH by } 13 \% \\
\text { Pericalcarine RH>LH by } 15 \% \\
\text { Rostral Anterior Cingulate LH>RH by } 26 \% \\
\text { Superior Frontal } \mathrm{LH}>\mathrm{RH} \text { by } 5 \% \\
\text { Superior Temporal } \mathrm{LH}>\mathrm{RH} \text { by } 7 \% \\
\text { Supramarginal } \mathrm{LH}>\mathrm{RH} \text { by } 8 \% \\
\text { Frontal Pole } \mathrm{RH}>\mathrm{LH} \text { by } 35 \% \\
\text { Transverse Temporal LH }>\mathrm{RH} \text { by } 34 \%\end{array}$ & $\begin{array}{l}\text { Isthmus Cingulate } \mathrm{RH}>\mathrm{LH} \text { by } 8 \% \\
\text { Middle Temporal } \mathrm{LH}>\mathrm{RH} \text { by } 7 \% \\
\text { Postcentral } \mathrm{LH}>\mathrm{RH} \text { by } 6 \% \\
\text { Superior Temporal } \mathrm{LH}>\mathrm{RH} \text { by } 6 \%\end{array}$ \\
\hline $\begin{array}{l}\text { Sex } \times \\
\text { Hemisphere }\end{array}$ & - & - & - \\
\hline
\end{tabular}

Abe O, Takao H, Gonoi W, et al:: Voxel-based analysis of the diffusion tensor. Neuroradiology. 2010; 52(8): 699-710. PubMed Abstract | Publisher Full Text

Acer N, Cankaya MN, Isci O, et al.: Estimation of cerebral surface area using vertical sectioning and magnetic resonance imaging: a stereological study. Brain Res. 2010; 1310: 29-36.

PubMed Abstract | Publisher Full Text

Bansal R, Hao X, Liu F, et al:: The effects of changing water content, relaxation times, and tissue contrast on tissue segmentation and measures of cortical anatomy in MR images. Magn Reson Imaging. 2013; 31(10): 1709-1730. PubMed Abstract | Publisher Full Text | Free Full Text

Barnes J, Ridgway GR, Bartlett J, et al.: Head size, age and gender adjustment in MRI studies: a necessary nuisance? Neuroimage. 2010; 53(4): 1244-1255. PubMed Abstract | Publisher Full Text

Barta P, Dazzan P: Hemispheric surface area: sex, laterality and age effects. Cereb Cortex. 2003; 13(4): 364-370.

PubMed Abstract | Publisher Full Text

Bostan AC, Dum RP, Strick PL: Cerebellar networks with the cerebral cortex and basal ganglia. Trends Cogn Sci. 2013; 17(5): 241-254.

PubMed Abstract | Publisher Full Text | Free Full Text

Brain Development Cooperative Group: Total and regional brain volumes in a population-based normative sample from 4 to 18 years: the NIH MRI Study of Normal Brain Development. Cereb Cortex. 2012; 22(1): 1-12.

PubMed Abstract | Publisher Full Text | Free Full Text

Bramen JE, Hranilovich JA, Dahl RE, et al:: Puberty influences medial temporal lobe and cortical gray matter maturation differently in boys than girls matched for sexual maturity. Cereb Cortex. 2011; 21(3): 636-646.

PubMed Abstract | Publisher Full Text | Free Full Text

Brun CC, Lepore N, Luders E, et al:: Sex differences in brain structure in auditory and cingulate regions. Neuroreport. 2009; 20(10): 930-935.

PubMed Abstract | Publisher Full Text | Free Full Text

Buckner RL, Head D, Parker J, et al:: A unified approach for morphometric and functional data analysis in young, old, and demented adults using automated atlas-based head size normalization: reliability and validation against manual measurement of total intracranial volume. Neuroimage. 2004; $23(2)$ : 724-738.

PubMed Abstract | Publisher Full Text

Bush EC, Allman JM: The scaling of white matter to gray matter in cerebellum and neocortex. Brain Behav Evol. 2003; 61(1): 1-5.

PubMed Abstract | Publisher Full Text

Crivello F, Tzourio-Mazoyer N, Tzourio C, et al.: Longitudinal assessment of global and regional rate of grey matter atrophy in 1,172 healthy older adults: modulation by sex and age. PLoS One. 2014; 9(12): e114478. PubMed Abstract | Publisher Full Text | Free Full Text

Dale AM, Fischl B, Sereno MI: Cortical surface-based analysis. I. Segmentation and surface reconstruction. Neuroimage. 1999; 9(2): 179-194.

PubMed Abstract | Publisher Full Text

Dekaban AS: Tables of cranial and orbital measurements, cranial volume, and derived indexes in males and females from $\mathbf{7}$ days to 20 years of age. Ann Neurol. 1977; 2(6): 485-491.

PubMed Abstract | Publisher Full Text

Desikan RS, Segonne F, Fischl B, et al:: An automated labeling system for subdividing the human cerebral cortex on MRI scans into gyral based regions of interest. Neuroimage. 2006; 31(3): 968-980.

PubMed Abstract | Publisher Full Text

Eyler LT, Prom-Wormley E, Panizzon MS, et al.: Genetic and environmental contributions to regional cortical surface area in humans: a magnetic resonance imaging twin study. Cereb Cortex. 2011; 21(10): 2313-2321. PubMed Abstract | Publisher Full Text | Free Full Text

Filipek PA, Richelme C, Kennedy DN, et al.: The young adult human brain: an MRI-based morphometric analysis. Cereb Cortex. 1994; 4(4): 344-360. PubMed Abstract | Publisher Full Text

Fischl B, Salat DH, Busa E, et al:: Whole brain segmentation: automated labeling of neuroanatomical structures in the human brain. Neuron. 2002; 33(3): 341-355.

PubMed Abstract | Publisher Full Text

Fischl B, Salat DH, van der Kouwe AJ, et al:: Sequence-independent segmentation of magnetic resonance images. Neuroimage. 2004; 23(Suppl 1): S69-84.

PubMed Abstract | Publisher Full Text

Fischl B, Sereno MI, Dale AM: Cortical surface-based analysis. II: Inflation, flattening, and a surface-based coordinate system. Neuroimage. 1999a; 9(2): 195-207.

PubMed Abstract | Publisher Full Text

Fischl B, Sereno MI, Tootell RB, et al:: High-resolution intersubject averaging and a coordinate system for the cortical surface. Hum Brain Mapp. 1999b; 8(4) 272-284.

PubMed Abstract | Publisher Full Text

Fjell AM, Westlye LT, Amlien I, et al:: Minute effects of sex on the aging brain: a multisample magnetic resonance imaging study of healthy aging and Alzheimer's disease. J Neurosci. 2009; 29(27): 8774-8783.

PubMed Abstract | Publisher Full Text | Free Full Text 
Goldstein JM, Seidman LJ, Horton NJ, et al.: Normal sexual dimorphism of the adult human brain assessed by in vivo magnetic resonance imaging. Cereb Cortex. 2001; 11(6): 490-497.

PubMed Abstract | Publisher Full Text

Good CD, Johnsrude I, Ashburner J, et al.: Cerebral asymmetry and the effects of sex and handedness on brain structure: a voxel-based morphometric analysis of 465 normal adult human brains. Neuroimage. 2001; 14(3): 685-700. PubMed Abstract | Publisher Full Text

Herculano-Houzel S, Mota B, Wong P, et al.: Connectivity-driven white matter scaling and folding in primate cerebral cortex. Proc Natl Acad Sci U S A. 2010; 107(44): 19008-19013.

PubMed Abstract | Publisher Full Text | Free Full Text

Herron TJ, Kang X, Woods DL: Dataset 1 in: Sex differences in cortical and subcortical human brain anatomy. F1000Research. 2015.

Data Source

Im K, Jo HJ, Mangin JF, et al.: Spatial distribution of deep sulcal landmarks and hemispherical asymmetry on the cortical surface. Cereb Cortex. 2010; 20(3): 602-611.

PubMed Abstract | Publisher Full Text

Im K, Jo HJ, Mangin JF, et al:: Spatial distribution of deep sulcal landmarks and hemispherical asymmetry on the cortical surface. Cereb Cortex. 2010; 20(3): 602-611.

PubMed Abstract | Publisher Full Tex

Im K, Lee JM, Lee J, et al:: Gender difference analysis of cortical thickness in healthy young adults with surface-based methods. Neuroimage. 2006; 31(1): 31-38.

PubMed Abstract | Publisher Full Text

Im K, Lee JM, Lyttelton O, et al:: Brain size and cortical structure in the adult human brain. Cereb Cortex. 2008; 18(9): 2181-2191.

PubMed Abstract | Publisher Full Text

Inano $\mathrm{S}$, Takao $\mathrm{H}$, Hayashi $\mathrm{N}$, et al: Effects of age and gender on

neuroanatomical volumes. J Magn Reson Imaging. 2013; 37(5): 1072-6.

PubMed Abstract | Publisher Full Text

Jiang Z, Dinov ID, Labus J, et al:: Sex-related differences of cortical thickness in patients with chronic abdominal pain. PLOS One. 2013; 8(9): e73932.

PubMed Abstract | Publisher Full Text | Free Full Text

Kang X, Herron TJ, Cate AD, et al:: Hemispherically-unified surface maps of human cerebral cortex: reliability and hemispheric asymmetries. PLOS One. 2012; 7(9): e45582.

PubMed Abstract | Publisher Full Text | Free Full Text

Kang X, Herron TJ, Ettlinger M, et al:: Hemispheric Asymmetries in Cortical and Subcortical Anatomy. Laterality 2015.

Publisher Full Tex

Karbowski J: Constancy and trade-offs in the neuroanatomical and metabolic design of the cerebral cortex. Front Neural Circuits. 2014; 8: 9

PubMed Abstract | Publisher Full Text | Free Full Text

Kim HJ, Kim N, Kim S, et al:: Sex differences in amygdala subregions: evidence from subregional shape analysis. Neuroimage. 2012; 60(4): 2054-2061.

PubMed Abstract | Publisher Full Text

Koolschijn PC, Crone EA: Sex differences and structural brain maturation from childhood to early adulthood. Dev Cogn Neurosci. 2013; 5: 106-118.

PubMed Abstract | Publisher Full Text

Lentini E, Kasahara M, Arver S, et al.: Sex differences in the human brain and the impact of sex chromosomes and sex hormones. Cereb Cortex. 2013; 23(10): 2322-2336

PubMed Abstract | Publisher Full Text

Leonard CM, Towler S, Welcome S, et al:: Size matters: cerebral volume influences sex differences in neuroanatomy. Cereb Cortex. 2008; 18(12): 2920-2931.

PubMed Abstract | Publisher Full Text | Free Full Text

Li W, van Tol MJ, Li M, et al.: Regional specificity of sex effects on subcortical volumes across the lifespan in healthy aging. Hum Brain Mapp. 2014; 35(1): 238-247.

PubMed Abstract | Publisher Full Text

Luders E, Gaser C, Narr KL, et al:: Why sex matters: brain size independen differences in gray matter distributions between men and women. $J$ Neurosci. 2009; 29(45): 14265-14270.

PubMed Abstract | Publisher Full Text | Free Full Text

Luders E, Narr KL, Thompson PM, et al.: Gender differences in cortical complexity. Nat Neurosci. 2004; 7(8): 799-800.

PubMed Abstract | Publisher Full Text

Luders E, Narr KL, Thompson PM, et al: Gender effects on cortical thickness and the influence of scaling. Hum Brain Mapp. 2006; 27(4): 314-324. PubMed Abstract | Publisher Full Text

Luders E, Toga AW: Sex differences in brain anatomy. Prog Brain Res. 2010; 186: 3-12.

PubMed Abstract | Publisher Full Tex

Lv B, Li J, He H, et al:: Gender consistency and difference in healthy adults revealed by cortical thickness. Neuroimage. 2010; 53(2): 373-382.

PubMed Abstract | Publisher Full Tex

Marcus DS, Wang TH, Parker J, et al:: Open Access Series of Imaging Studies (OASIS): cross-sectional MRI data in young, middle aged, nondemented, and demented older adults. J Cogn Neurosci. 2007; 19(9): 1498-1507.

PubMed Abstract | Publisher Full Text
Neufang S, Specht K, Hausmann M, et al.: Sex differences and the impact of steroid hormones on the developing human brain. Cereb Cortex. 2009; 19(2): 464-473.

PubMed Abstract | Publisher Full Tex

Nopoulos P, Flaum M, O'Leary D, et al.: Sexual dimorphism in the human brain evaluation of tissue volume, tissue composition and surface anatomy using magnetic resonance imaging. Psychiatry Res. 2000; 98(1): 1-13.

PubMed Abstract | Publisher Full Text

Pakkenberg B, Gundersen HJ: Neocortical neuron number in humans: effect of sex and age. J Comp Neurol. 1997; 384(2): 312-320.

PubMed Abstract | Publisher Full Text

Peper JS, Brouwer RM, Schnack HG, et al.: Sex steroids and brain structure in pubertal boys and girls. Psychoneuroendocrinology. 2009; 34(3): 332-342.

PubMed Abstract | Publisher Full Text

Peters M, Jancke L, Staiger JF, et al:: Unsolved problems in comparing brain sizes in Homo sapiens. Brain Cogn. 1998; 37(2): 254-285.

PubMed Abstract | Publisher Full Text

Pienaar R, Fischl B, Caviness V, et al.: A Methodology for Analyzing Curvature in the Developing Brain from Preterm to Adult. Int J Imaging Syst Technol. 2008; 18(1): 42-68.

PubMed Abstract | Publisher Full Text | Free Full Text

Ronan L, Doherty CP, Delanty N, et al:: Quantitative MRI: a reliable protocol for measurement of cerebral gyrification using stereology. Magn Reson Imaging. 2006; 24(3): 265-272.

PubMed Abstract | Publisher Full Text

Ropele S, Seewann A, Gouw AA, et al:: Quantitation of brain tissue changes associated with white matter hyperintensities by diffusion-weighted and magnetization transfer imaging: the LADIS (Leukoaraiosis and Disability in the Elderly) study. J Magn Reson Imaging. 2009; 29(2): 268-274.

PubMed Abstract | Publisher Full Tex

Ruigrok AN, Salimi-Khorshidi G, Lai MC, et al.: A meta-analysis of sex differences in human brain structure. Neurosci Biobehav Rev. 2014; 39(100): 34-50. PubMed Abstract | Publisher Full Text | Free Full Text

Sacher J, Neumann J, Okon-Singer $\mathrm{H}$, et al:: Sexual dimorphism in the human brain: evidence from neuroimaging. Magn Reson Imaging. 2013; 31(3): $366-375$

PubMed Abstract | Publisher Full Tex

Salat $\mathrm{DH}$, Buckner RL, Snyder AZ, et al:: Thinning of the cerebral cortex in aging. Cereb Cortex. 2004; 14(7): 721-730.

PubMed Abstract | Publisher Full Text

Savic I, Arver S: Sex Differences in cortical thickness and their possible genetic and sex hormonal underpinnings. Cereb Cortex. 2014; 24(12): 3246-3257.

PubMed Abstract | Publisher Full Text

Sowell ER, Peterson BS, Kan E, et al:: Sex differences in cortical thickness mapped in 176 healthy individuals between 7 and 87 years of age. Cereb Cortex. 2007; 17(7): 1550-1560.

PubMed Abstract | Publisher Full Text | Free Full Text

Sowell ER, Thompson PM, Leonard CM, et al.: Longitudinal mapping of cortica thickness and brain growth in normal children. J Neurosci. 2004; 24(38): 8223-8231.

PubMed Abstract | Publisher Full Tex

Szabo CA, Lancaster JL, Lee S, et al.: MR imaging volumetry of subcortical structures and cerebellar hemispheres in temporal lobe epilepsy. AJNR Am J Neuroradiol. 2006; 27(10): 2155-2160.

PubMed Abstract

Thambisetty M, Wan J, Carass A, et al.: Longitudinal changes in cortica thickness associated with normal aging. Neuroimage. 2010; 52(4):

1215-1223.

PubMed Abstract | Publisher Full Text | Free Full Text

Toro R, Perron M, Pike B, et al:: Brain size and folding of the human cerebra cortex. Cereb Cortex. 2008; 18(10): 2352-2357.

PubMed Abstract | Publisher Full Text

Van Essen DC: A Population-Average, Landmark- and Surface-based (PALS) atlas of human cerebral cortex. Neuroimage. 2005; 28(3): 635-662.

PubMed Abstract | Publisher Full Text

Van Essen DC, Glasser MF, Dierker DL, et al: Parcellations and hemispheric asymmetries of human cerebral cortex analyzed on surface-based atlases. Cereb Cortex. 2012; 22(10): 2241-2262.

PubMed Abstract | Publisher Full Text | Free Full Text

Ventura-Antunes L, Mota B, Herculano-Houzel S: Different scaling of white matter volume, cortical connectivity, and gyrification across rodent and primate brains. Front Neuroanat. 2013; 7: 3 .

PubMed Abstract | Publisher Full Text | Free Full Text

Winkler AM, Kochunov $\mathrm{P}$, Blangero J, et al.: Cortical thickness or grey matter volume? The importance of selecting the phenotype for imaging genetics studies. Neuroimage. 2010; 53(3): 1135-1146.

PubMed Abstract | Publisher Full Text | Free Full Text

Winkler AM, Sabuncu MR, Yeo BT, et al:: Measuring and comparing brain cortical surface area and other areal quantities. Neuroimage. 2012; 61(4): 1428-1443. PubMed Abstract | Publisher Full Text | Free Full Text

Zhang K, Sejnowski TJ: A universal scaling law between gray matter and white matter of cerebral cortex. Proc Natl Acad Sci U S A. 2000; 97(10): 5621-5626. PubMed Abstract | Publisher Full Text | Free Full Text 


\section{Open Peer Review}

\section{Current Peer Review Status:}

\section{Version 1}

Reviewer Report 05 May 2015

https://doi.org/10.5256/f1000research.6660.r8267

(C) 2015 Rippon G. This is an open access peer review report distributed under the terms of the Creative Commons Attribution License, which permits unrestricted use, distribution, and reproduction in any medium, provided the original work is properly cited.

\section{Gina Rippon}

Aston Brain Centre, School of Life and Health Sciences (Psychology), Aston University, Birmingham, UK

Methodologically, this study is sound although it should be noted that, with respect to intracranial volume (ICV) estimations, there was apparently no correction for height and weight (a flaw in the Ruigrok et al, 2014 review which these authors themselves acknowledge). Matching of participants for levels of education is also a welcome addition to standard practice.

My substantive comments are confined to observations on the disconnect between the findings as reported in the paper itself and those inferred in the abstract (and indeed in the title of the paper). The paper is entitled "Sex differences in cortical and subcortical human brain anatomy" and the abstract includes the sentence; "Significant sex differences were observed". Yet if we look at what was actually found, at the very least the abstract should report "very few significant sex differences were observed" and, by rights, the paper should be entitled: "On the failure to find sex differences...." Or "Few sex differences in cortical and subcortical human brain anatomy"

A brief summary of the results of the search for sex differences follows:

Looking at "whole hemisphere sex differences in cortical thickness, area and folding", it is reported that there were no sex differences in thickness and folding, and a correlation with area was reduced to a trend when there was a correction for ICV (pg. 6).

Looking at sex differences in cranial structures there were no differences in thickness and folding (pg. 6)

There were sex differences in frontal lobe area $(M>F)$, but no area differences at the parcel level in any lobe (pg. 6) and no significant sex by hemisphere interactions in any parcel in any lobe in thickness, area or BED (pg. 7)

Of the 7 subcortical structures, only the amygdala showed significant sex differences ( $M>F$ ). The authors acknowledge in their discussion "Sex differences are generally small in the current 


\begin{abstract}
study (pg.7) " and that "effect sizes were small" (pg8) and even "our sex difference results resemble those of researchers who found that individual difference in overall brain size explain far more variance in brain anatomy that do residual difference due to sex". (pg. 8).
\end{abstract}

On balance, the findings of this paper are that there are very few, if any, substantive, sex differences and, when appropriate corrections are made, these may well disappear.

I would draw the authors' (and indeed any readers') attention to the coverage of this type of issue raised in a recent paper from our group (Rippon et al., 2014).

My concerns are that, given the title and the claims in the Abstract, this paper will be taken as an addition to the body of evidence proving that there are reliably identifiable differences between the brains of females and males. I think the authors should be invited to recast their paper to acknowledge the difficulties they have encountered in demonstrating any "Sex Differences in cortical and subcortical human brain anatomy".

Competing Interests: No competing interests were disclosed.

I confirm that I have read this submission and believe that I have an appropriate level of expertise to confirm that it is of an acceptable scientific standard, however I have significant reservations, as outlined above.

Reviewer Report 16 April 2015

https://doi.org/10.5256/f1000research.6660.r8272

(c) 2015 Jäncke L. This is an open access peer review report distributed under the terms of the Creative Commons Attribution License, which permits unrestricted use, distribution, and reproduction in any medium, provided the original work is properly cited.

\title{
Lutz Jäncke
}

Department of Psychology (Neuropsychology) and INAPIC, University of Zurich, Zurich, Switzerland

In general this is an interesting and important study again showing that brain size (or ICV) is quite important for morphometric analyses and especially when comparing the sexes. In this context I would like to draw the attention of the authors to a recent paper paper of our group (Jäncke et al., 2015 ) in which actually the same has been done (with a few exceptions) as in this study. However, in that paper the authors have used a much larger sample $(n=856)$ and identified small or even non-existing sex influences on several brain compartments when ICV and/or FBV has been used as control variable. This finding and the finding report by the authors is in line with several studies of our group (Jäncke et al., 1997; Lüders et al., 2002) but also with studies from other groups (Leonard et al., 2008, Lemaître et al., 2005). Thus, sex differences are small or non-existing when one use 
brain size corrections. However, what is unknown so far (in my opinion) is whether there are indeed some sex differences, which are still there but which we do not "see" using the more or less cars methods we are all using. Thus, we have to be carefully in making to firm conclusion in terms of using potential anatomical sex differences as the basis of possible sex-gender-differences in behavior. Thus, the authors should add some comments on that, too.

Competing Interests: No competing interests were disclosed.

I confirm that I have read this submission and believe that I have an appropriate level of expertise to confirm that it is of an acceptable scientific standard.

The benefits of publishing with F1000Research:

- Your article is published within days, with no editorial bias

- You can publish traditional articles, null/negative results, case reports, data notes and more

- The peer review process is transparent and collaborative

- Your article is indexed in PubMed after passing peer review

- Dedicated customer support at every stage

For pre-submission enquiries, contact research@f1000.com 